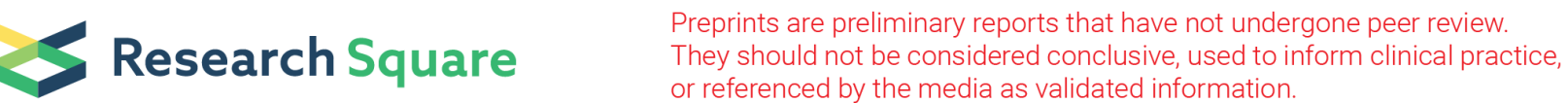

\section{New ternary water-soluble support from self- assembly of $\beta$-cyclodextrin-ionic liquid and an anionic polymer for a dialysis device}

\section{Asmaa Bouyahya}

Rouen University: Universite de Rouen

Berthe-Sandra Sembo-Backonly

Rouen University: Universite de Rouen

\section{Audrey Favrelle-Huret}

Université des Sciences et Technologies de Lille: Universite de Lille

\section{Sébastien Balieu}

Université de Rouen: Universite de Rouen

\section{Frédéric Guillen}

Universite de Toulouse 3: Universite Toulouse III Paul Sabatier

\section{Valérie Mesnage}

Universite de Rouen

\section{Carole Karakasyan-Dia}

Rouen University: Universite de Rouen

\section{Mohammed Lahcini}

Université Cadi Ayyad Faculté des Sciences et Techniques Marrakech: Universite Cadi Ayyad Faculte des

Sciences et Techniques Gueliz

\section{Didier Le Cerf}

Universite de Rouen UFR des Sciences et Techniques

Géraldine Gouhier ( $\nabla$ geraldine.gouhier@univ-rouen.fr)

Université de Rouen: Universite de Rouen https://orcid.org/0000-0002-3852-1827

\section{Research Article}

Keywords: Ionic liquid, $\beta$-Cyclodextrin, Host-guest inclusion complex, Poly(styrene sulfonate), Metathesis, Pollutant, Dialyzer

Posted Date: May 3rd, 2021

DOI: https://doi.org/10.21203/rs.3.rs-395636/v1 
License: (c) (i) This work is licensed under a Creative Commons Attribution 4.0 International License. Read Full License

Version of Record: A version of this preprint was published at Environmental Science and Pollution Research on September 14th, 2021. See the published version at https://doi.org/10.1007/s11356-02116374-0. 


\section{Abstract}

We developed a new hybrid material resulting from an innovative supramolecular tripartite association between an ionic liquid covalently immobilized on primary $\beta$-cyclodextrins rim and an anionic watersoluble polymer. Two hydrophilic ternary complexes based on native and permethylated $\beta$-cyclodextrins substituted with an ionic liquid and immobilized on poly(styrene sulfonate) (CD-IL ${ }^{+} P S S^{-}$and $\left.\mathrm{CD}(\mathrm{OMe}) \mathrm{IL}^{+} \mathrm{PSS}^{-}\right)$were obtained by simple dialysis with a cyclodextrin maximal grafting rate of $25 \%$ and $20 \%$ on the polymer, respectively. These polyelectrolytes are based on electrostatic interactions between the opposite charges of the imidazolium cation of the ionic liquid and the poly(styrene sulfonate) anion. The inclusion properties of the free cavities of the cyclodextrins and the synergic effect of the polymeric matrix were studied with three reference guests such as phenolphthalein, $p$-nitrophenol, and 2anilinonaphthalene-6-sulfonic acid using UV-visible, fluorescent, and NMR spectroscopies. The support has been applied successfully in dialysis device to extract and concentrated aromatic model molecule. This simple and flexible synthetic strategy opens the way to new hybrid materials useful for fast and lowcost ecofriendly extraction techniques relevant for green analytical chemistry.

\section{Introduction}

Ionic liquids (ILs) are a broad class of salts with melting points below $100^{\circ} \mathrm{C}$ and are generally composed of an organic cation (such as imidazolium, pyridinium, phosphonium or ammonium cation), and an organic or inorganic anion. Ionic liquids are known to be flexible solvents because most of their properties, such as thermal stability, electrolytic conductivity, viscosity, and miscibility with other solvents, can be easily tuned by modifying either the anionic or the cationic part of the salt. Their low volatility makes them especially relevant in the context of green chemistry by facilitating their confinement and recycling. They have therefore been used in various domains of chemistry including among others: separation chemistry, analytical chemistry to improve the sensitivity, selectivity, and detection limit of analytical applications (Pandey 2006; Koel 2016; Anderson and Clark 2018) and in the development of new materials (Hallett and Welton 2011; Hayes et al. 2015).

$\beta$-cyclodextrin (CD) is a macrocyclic oligosaccharide composed of seven a-D-(1,4)-glucopyranoside moieties (D'Souza 1998). This natural compound is produced from starch by the action of glucanotransferase. Its toroidal shape is lined with C-6 primary hydroxyl groups on the narrow rim and C2 and C-3 secondary hydroxyl groups on the wider rim. Thus, this cavity can welcome hydrophobic molecules in aqueous media thanks to van der Waals force, hydrophobic interaction, electrostatic affinity, dipole-dipole interaction, and hydrogen bonding. This host-guest inclusion property has found many industrial applications in the formulations, extraction, and analytical processes, in domains as diverse as pharmaceutical, food, cosmetic, and textile chemistry. The covalent (Fig. 1a-d, 1f) or non-covalent (Fig. 1e) associations between ionic liquid and cyclodextrin have opened the way to new applications in function of the nature of the selected support. 
In the majority of the reported cases, the IL is covalently bound to the CD rim. As an example, ionic liquid grafted by the nitrogen atom of imidazolium on the primary face of $\beta$-cyclodextrin was immobilized on modified silica and used as chiral support in high-performance liquid chromatography (Rahim et al. 2016a; Rahim et al. 2016b), in capillary gas chromatography (Zhang et al. 2011) or in capillary electrophoresis (Zhou et al. 2017) (Fig. 1a). The presence of the ionic species improved the enantioseparation of $\beta$-blockers and flavonoids thanks to the formation of intermolecular inclusion complex but also owing to an original $\pi-\pi$ interaction between the aromatic guest and the imidazolium cycle (Rahim et al. 2016a; Rahim et al. 2016b). The original electrochemical properties of ionic liquids and the high supramolecular recognition properties of cyclodextrins were also tested on metallic supports such as Pt-Co (Zhao et al. 2010), graphite (Mohamad et al. 2015; Rasdi et al. 2016), $\mathrm{Fe}_{3} \mathrm{O}_{4}$ (Sinniah et al. 2015, Bahadorikhalili et al. 2019), Au-graphene oxide (Li et al. 2016) producing new nanoparticles and hybrid nanomaterials (Fig. 1b). The ionic liquid playing the role of supported stabilizer electrolyte provides higher sensitive carbon paste electrodes leading to environmentally-friendly electrochemical sensors for non-enzymatic glucose reaction (Zhao et al. 2010) or to detect 2,4-dichlorophenol (Mohamad et al. 2015; Rasdi et al. 2016). In the same way, magnetite nanoparticles coated with $\beta$-CD-IL produced new electrode material able to recognize bisphenol A (Sinniah et al. 2015) and sunset yellow (Li et al. 2016). Finally, magnetic starch based on CD-IL was used as organic catalyst (Bahadorikhalili et al. 2019).

Green analytical chemistry is also based on low cost and fast eco-friendly extraction techniques possible thanks to the ionic liquid properties (Kissoudi and Samanidou 2018). Immobilization of IL on polymers of $\beta$-CD produced macroporous insoluble material used as Solid Phase Extraction (SPE) tool to extract and analyze traces of organic and metal toxic derivatives in water (Mahlambi et al. 2010, 2011; Raoov et al. 2013, 2014a, 2014b), drug (Zhou and Zhu 2014), blood (Qin and Zhu 2017), and pyrethroids (Gao et al. 2020) (Fig. 1c). Vortex-assisted liquid-liquid microextraction (Yang et al. 2015) or effervescence-assisted dispersive solid-phase extraction (Wu et al. 2016) methods using a magnetic $\beta$-CD-IL sorbed on attapulgite clay (Fig. 1b) were also used for the fluorometric determination of aliphatic amines pollutant and fungicide detection in honey and juice, respectively. Other magnetic preconcentration procedure based on ionic liquid- $\beta$-cyclodextrin polymer attached to $\mathrm{Fe}_{3} \mathrm{O}_{4}$ nanoparticles achieved the speciation analysis of manganese in water samples (Quin et al. 2016), herbicides in fruits and vegetables (Bakheet et al. 2016a), parabens in cosmetics (Yusoff et al. 2017), rhodamine B in food samples (Bakheet and Zhu 2017b), and PFOA, PFOS and Cr(VI) in wastewater (Badruddoza et al. 2017) (Fig. 1d).

The supramolecular interactions between the cationic or anionic parts of ionic liquid and the hydrophobic cavity of cyclodextrin (IL/CD) are well known and have found applications in polymer chemistry, molecular devices, and nanoscience (Rogalski et al. 2013; Mofaddel et al. 2016). The addition of an anionic polymer to this IL/CD combination led to new supramolecular architectures. In 2004 Amiel et al. described the first water-soluble ternary complexes mixing a polymer of $\beta-C D s$, a cationic surfactant, and anionic polymers. These polyelectrolyte complexes were based on two interactions: electrostatic interactions between the opposite charges of the surfactant and the poly(styrene sulfonate) (PSS) and, inclusion complex interactions between the lipophilic part of the surfactant and the neutral $\beta$-cyclodextrin 
polymer (Fig. 1e) (Galant and Amiel 2004; Amiel et al. 2004; Antoniuk and Amiel 2016). The formation of aggregates was observed when this interpolyelectrolyte complex was formed in stoichiometric conditions reducing the water solubility of the system. As an application, DNA extraction mimicking a self-assembly biological process by forming supramolecular multilayers has been developed (Antoniuk and Amiel 2016). The reversibility of the system has a great potential for the formation of microcapsules and modified surfaces in the gene delivery domain.

Surprisingly the non-covalent interaction between an ionic liquid covalently bound to a cyclodextrin and an anionic polymer has been unexplored until now (Fig. 1f). We selected the commercially available, water-soluble sodium poly(styrene sulfonate) $\left(\mathrm{PSS}^{-} \mathrm{Na}^{+}\right)$as an anionic polymer exchanger. Sulfonate function is a strong electrolyte whose charge is little affected by a change in $\mathrm{pH}$ value. The formation of the complex between anionic PSS and amphiphilic IL has been already studied and has found applications as magnetic nanoparticles for conductive membrane (Jiao and al. 2015; Barhoumi et al. 2016). When long-chain imidazolium is used as a surfactant, electrostatic and hydrophobic interactions drive self-assembly between the PSS backbones and the alkyl tail to form ordered micelles with specific surface tension useful in colloid and interface sciences. Herein, we exploited the ionic strength between PSS and a non-amphiphilic butylimidazolium cation grafted on $\beta-C D\left(C D-\mathrm{IL}^{+} X^{-}\right)$to form a new hydrophilic extractive CD-IL ${ }^{+} \mathrm{PSS}^{-}$tool. The coupling between the two entities will be carried out by simple ion metathesis between the ionic polymer and the IL covalently immobilized on the macrocycle (Fig. 2). By avoiding any intramolecular inclusion of the ionic liquid, this new assembly will keep the cavity of the $\beta$-cyclodextrin available and consequently improve the potential of extraction and preconcentration of molecules of interest. Moreover, this aqueous soluble support will extend the field of analytical applications.

The host-guest inclusion properties were studied using three reference guests, namely phenolphthalein, $p$ nitrophenol, and 2-anilino-6-naphtalene sulfonate (2,6-ANS), using UV-visible, fluorescence, and NMR spectroscopies. Finally, this innovative support has been tested to extract and concentrate 2,6-ANS as a model in a pore water dialysis sampler.

\section{Materials And Instruments}

The equipment, materials, methods, synthesis and characterization details of products $2-4,7,9,11-13$ are available in the experimental section. Graphs of $p$-nitrophenol inclusion study (absorbance and job plot, stability constants table), and NOESY NMR of inclusion complex of 13:2,6-ANS obtained with the dialyzer were also reported.

\section{Results And Discussion Synthesis of supports}

The ionic liquid has been designed with a carboxylic acid function to bind the macrocycle via an amide bonding and with a flexible carbon linker of five carbon atoms (long enough to avoid steric hindrance but 
short enough to prevent intramolecular inclusion complexation). Two routes have been developed leading to two different ILs with $\mathrm{PF}_{6}{ }^{-}$and $\mathrm{Br}^{-}$counter ions. The first one was obtained in four steps (Fig. 3), when the second one in only one step by microwave activation (Fig. 4).

The ring-opening of $\varepsilon$-caprolactone 1 by methyltrichlorosilane $\left(\mathrm{MeSiCl}_{3}\right)$ in presence of $\mathrm{Nal}$ in $\mathrm{ACN}$ led to methyl 6-halohexanoate 2 (as a 83/17 mixture of the iodo and chloro derivatives). Nucleophilic substitution of the haloester 2 by methylimidazole formed the ionic adduct 3 with 78\% yield (Mincheva et al. 2007). After the saponification step, the ion metathesis by addition of $\mathrm{KPF}_{6}$ in $\mathrm{ACN}$ of $\mathbf{4}$ generated the desired IL 5 with good yield and was confirmed by ${ }^{1} \mathrm{H},{ }^{31} \mathrm{P}$ and ${ }^{19} \mathrm{~F}$ NMR spectroscopies. Thus, the chemical shift observed for the protons and carbons of the imidazolium group validated this total conversion. As the $\mathrm{PF}_{6}{ }^{-}$anion is more hydrophobic than the iodide, we expected that the metathesis with $\mathrm{PSS}^{-} \mathrm{Na}^{+}$to give a water-soluble polymer complex would be easier. Moreover, the presence of phosphorus atom would facilitate the follow-up of the reaction by NMR spectroscopy. An alternative strategy was developed to obtain the IL $\mathbf{7}$ with bromine as a counter ion by using commercial 6 -bromohexanoic acid $\mathbf{6}$ and 1-methylimidazole under microwave activation with $88 \%$ yield in only ten minutes (Fig. 4).

The immobilization of IL 5 on TRIMEB-NH 28 (Moutard et al. 2002; Tang and $\mathbf{~ N g}$ 2008; Nielsen et al. 2010; Jicsinszky et al. 2016; Cyclolab) was obtained after activation of the acid function as an acyl chloride in $40 \%$ yield (Fig. 5 ).

The amidation reaction between CD-NH 10 (Moutard et al. 2002; Tang and Ng 2008; Nielsen et al. 2010; Jicsinszky et al. 2016; Cyclolab) and IL 7 was performed in presence of coupling agent TBTU with 88\% after dialysis against water (Fig. 6). Then, a similar protocol was applied with TRIMEB-NH 8 leading to $\mathrm{CD}(\mathrm{OMe}) \mathrm{IL}^{+} \mathrm{PF}_{6}-9$ in $90 \%$ yield.

The metathesis reaction between $\mathrm{CD}(\mathrm{OMe})-\mathrm{IL}^{+} \mathrm{PF}_{6}-9$ or $\mathrm{CD}-\mathrm{IL}^{+} \mathrm{Br}^{-} 11$ and $\mathrm{PSS}^{-} \mathrm{Na}^{+}$was performed under mild conditions by dialysis against deionized water using a $500 \mathrm{Da}$ membrane during two days, shifting the equilibrium by eliminating $\mathrm{NaPF}_{6}$ and $\mathrm{NaBr}$ salts (Fig. 7). After lyophilization $\mathrm{CD}(\mathrm{OMe}) \mathrm{IL}^{+} \mathrm{PSS}-12$ and CD-IL ${ }^{+} P S S-13$ complexes were obtained with high purities. ${ }^{19} \mathrm{~F}$ and ${ }^{31} \mathrm{P}$ NMR analysis revealed the presence of $\mathrm{NaPF}_{6}$ salt in the dialysate in the preparation of complex 12.

Various ratios of $\mathrm{CD}(\mathrm{OMe})-\mathrm{IL}^{+} \mathrm{PF}_{6}{ }^{-} \mathbf{9} / \mathrm{SS}^{-} \mathrm{Na}^{+}$(Styrene Sulfonate SS) varying from $1 / 25$ to $1 / 1$ were tested for the metathesis reaction (Table 1). The size exclusion chromatography analysis (SEC/MALS/VD/DRI) confirmed the good purity of our samples (Fig. 8A) and showed a shift of peaks at lower elution volume with the grafting of CD 9 on PSS in comparison to PSS (Fig. 8B) due to the increase of the molecular weights and the chain length. A calculus-based on the number average molecular weight led to the real ratio of immobilization on polymer evaluated from 1/49 to 1/4 (CD-IL/SS ratio) which correspond to a grafting efficiency ranging from $25-57 \%$. We observed a large increase in water solubility of the CD derivatives in presence of PSS polymer. 


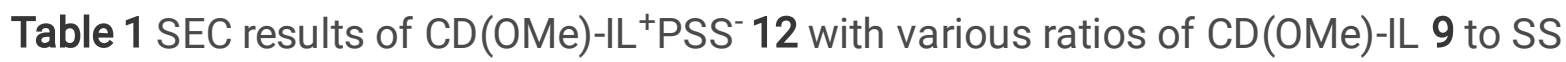

\begin{tabular}{|llllll|}
\hline $\begin{array}{l}\text { Theoretical } \\
\text { Ratio } \\
\text { CD(OMe)-IL 9/SS }\end{array}$ & $\begin{array}{l}M_{n} \\
(\mathbf{g} / \mathrm{mol})\end{array}$ & $\begin{array}{l}M_{w} \\
(\mathbf{g} / \mathrm{mol})\end{array}$ & $\begin{array}{l}\mathrm{Rh}^{\mathrm{a}} \\
(\mathrm{nm})\end{array}$ & $\begin{array}{l}\text { Experimentalratio } \\
\text { CD-IL } 9 / \mathrm{SS}\end{array}$ & $\begin{array}{l}\text { Grafting } \\
\text { efficiency }^{c}\end{array}$ \\
\hline $\mathbf{0 / 1}$ & 45,000 & 68,000 & 10.4 & - & - \\
\hline $\mathbf{1 / 2 5}$ & 53,000 & 80,000 & 10.8 & $1 / 44$ & $57 \%$ \\
\hline $\mathbf{1 / 2 0}$ & 52,000 & 84,000 & 12.3 & $1 / 49$ & $41 \%$ \\
\hline $\mathbf{1 / 1 5}$ & 52,000 & 94,000 & 12.1 & $1 / 49$ & $31 \%$ \\
\hline $\mathbf{1 / 5}$ & 73,000 & 121,000 & 13.3 & $1 / 12$ & $42 \%$ \\
\hline $\mathbf{1 / 1}$ & 132,000 & 350,000 & 16.4 & $1 / 4$ & $25 \%$ \\
\hline
\end{tabular}

a weight average hydrodynamic radius

${ }^{b} \mathrm{x}=[\mathrm{Mo}(\mathrm{CD}-\mathrm{IL}) \mathrm{xMn}(\mathrm{PSS})] /\left[\left[\left(\mathrm{Mn}\left(\mathrm{CD}-\mathrm{IL}^{+} \mathrm{PSS}-\mathrm{Mn}(\mathrm{PSS})\right] \mathrm{xMo}(\mathrm{PSS})\right]\right.\right.$ with $\mathrm{Mo}(\mathrm{CD}-\mathrm{IL})=1579$

$\mathrm{g} / \mathrm{mol}$ and $\mathrm{Mo}(\mathrm{PSS})=207 \mathrm{~g} / \mathrm{mol}$

${ }^{c} \mathrm{x}($ theoretical)/x (experimental) $\times 100$

Similar immobilization rates were observed when using theoretical ratios of $1 / 25,1 / 20$, and $1 / 15$; the overlapping peaks revealed no modification of the conformation of the polymer in solution even when a ratio of $1 \mathrm{CD}$ for 12 styrene sulfonate (SS) moieties was obtained. For the last trial (theoretical ratio 1/1) a higher dispersity $(B=2.6)$ of molecular weight due to a modification of the polymeric organization (aggregation) was detected. Thereafter the binding of $\mathrm{CD}^{-\mathrm{IL}^{+}} \mathrm{Br}^{-} 11$ and $\mathrm{PSS}^{-} \mathrm{Na}^{+}$was performed at two theoretical ratios of $1 / 20$ and $1 / 10$, and the experimental ratios of $1 / 25$ and $1 / 20$ were obtained, respectively, with the conservation of the initial conformation of the polymer (Table 2). 
Table 2

SEC analysis of $C D-\mathrm{IL}^{+} \mathrm{PSS} \mathrm{S}^{-13}$ with various ratios

\begin{tabular}{|c|c|c|c|c|c|}
\hline Theoretical & $M_{n}$ & $M_{w}$ & $\mathrm{Rh}$ & Experimental & Grafting \\
\hline Ratio & $\mathrm{g} / \mathrm{mol}$ & $\mathrm{g} / \mathrm{mol}$ & $\mathrm{nm}$ & ratio ${ }^{a}$ & efficiencyb \\
\hline \multicolumn{4}{|l|}{ CD-IL 11/SS } & \multicolumn{2}{|l|}{ CD-IL 11/SS } \\
\hline $1 / 20$ & 49,000 & 87,000 & 10.9 & $1 / 25$ & $80 \%$ \\
\hline $1 / 10$ & 60,000 & 98,000 & 11.5 & $1 / 20$ & $50 \%$ \\
\hline \multicolumn{6}{|c|}{$\begin{array}{l}\mathrm{a} x=[\mathrm{Mo}(\mathrm{CD}-\mathrm{IL}) \times \mathrm{Mn}(\mathrm{PSS})] /\left[\left[\left(\mathrm{Mn}\left(\mathrm{CD}-\mathrm{IL}^{+} \mathrm{PSS}-\mathrm{Mn}(\mathrm{PSS})\right] \times \mathrm{Mo}(\mathrm{PSS})\right] \text { with } \mathrm{Mo}(\mathrm{CD}-\mathrm{IL})=1312.5 \mathrm{~g} / \mathrm{mol}\right.\right. \\
\text { and } \mathrm{Mo}(\mathrm{PSS})=207 \mathrm{~g} / \mathrm{mol}\end{array}$} \\
\hline \multicolumn{6}{|c|}{${ }^{b} x($ theoretical)/x (experimental) $\times 100$} \\
\hline
\end{tabular}

As expected, a higher CD-IL/SS ratio generated higher binding efficiency on PSS. Better immobilization rates were obtained with CD-IL 11 (80\% for $1 / 25$ ratio) than methylated CD(OMe)-IL 9 (41\% for 1/49 ratio) due to higher water solubility.

\section{Inclusion Complex Studies}

The formation of the host-guest complex depends on the functionalization of the CD. A comparative study has been performed with all non-methylated and methylated CDs derivatives and their precursors to evaluate the influence of each modification. Three reference molecules were tested: phenolphtalein (PP), p-nitrophenol (PNP), and 2-anilinonaphthalene-6-sulfonic acid (2,6-ANS) (Fig. 9).

$\mathrm{PP}$ is known to form an inclusion complex with $\beta-C D$ with a stability constant (Ks) evaluated by UVVisible spectroscopy to $191 \mathrm{M}^{-1}$ (Eftink and Harrison 1981; Wang and Song 2007; Khalafi and Rafiee 2013). At basic $\mathrm{pH}$ (10.5), the pink PP color disappears in presence of CD generating a decrease in absorbance. The accessibility of the cavity of the macrocycles in polymer matrix will also be tested with PNP known as a fungicide derivative $\left(K s=204 \mathrm{M}^{-1}\right)$ (Tagushi 1986; Gelb and al. 1995) and 2,6-ANS (Ks= $\left.2220 \mathrm{M}^{-1}\right)$ (Wagner and Fitzpatrick 2000; Favrelle et al. 2015) a fluorescent probe.

Firstly, the inclusion of PP in native $\beta-C D$ was tested with various CD/PP ratios ranging from 1 to 25 equivalents. A complete inclusion was observed when 20 equivalents of $C D$ were used (Table 3 ). 
Table 3

Percentage of inclusion of PP in CDs

\begin{tabular}{|llll|}
\hline Equivalent of CD & $\boldsymbol{\beta}-\mathrm{CD}$ & TRIMEB & $\mathbf{C D}(\mathbf{O M e})-\mathrm{IL}^{+} \mathrm{PSS}^{-12 *}$ \\
\hline 1 & $70 \%$ & $0 \%$ & $16 \%$ \\
\hline 5 & $90 \%$ & $0 \%$ & $22 \%$ \\
\hline 10 & $93 \%$ & $0 \%$ & - \\
\hline 20 & $94 \%$ & $0 \%$ & $25 \%$ \\
\hline 25 & $97 \%$ & $0 \%$ & $25 \%$ \\
\hline *1/44 CD-IL/SS experimental ratio & $26 \%$ \\
\hline
\end{tabular}

The presence of an ionic liquid linker did not improve the water dissolution of $\mathrm{CD}(\mathrm{OMe})-\mathrm{IL}^{+} \mathrm{PF}_{6}{ }^{-}$9. The presence of methoxy groups on permethylated TRIMEB inhibited all inclusion properties of PP whatever the number of equivalents of the host. Similar negative results were obtained with $\mathrm{CD}(\mathrm{OMe})-\mathrm{NH}_{2} \mathbf{8}$ and $\mathrm{CD}(\mathrm{OMe})-\mathrm{IL}^{+} \mathrm{PF}_{6}{ }^{-}$9. As the intermolecular inclusion of counter ion $\mathrm{PF}_{6}{ }^{-}$was already reported in the literature with a long IL carbon chain, ${ }^{31}$ the same experiment was performed using iodide anion, and the same result was obtained, excluding a competitive insertion of $\mathrm{PF}_{6}{ }^{-}$anion of 9 into the cavity. The experiment was carried out on $\mathrm{CD}(\mathrm{OMe}) \mathrm{IL}^{+} \mathrm{PSS}-12$ with grafting of 1/44 CD-IL/SS and inclusion of PP varying between $16 \%$ and $26 \%$ was observed, probably due to an increase of water solubility of the complex and better accessibility to CD cavity once immobilized on the polymer backbone. ROESY NMR experiment was performed in $\mathrm{D}_{2} \mathrm{O}$ to confirm the absence of intramolecular self-inclusion complex of the ionic liquid chain into the cavity of the cyclodextrin 9 . The absence of cross-peaks between protons of the ionic liquid chain (1.44 ppm) or imidazolium cycle $(8.5 \mathrm{ppm})$ and b-CD moiety fully supports this conclusion (empty scare in Fig. 10). Finally, as the dialysis step eliminated all traces of $\mathrm{PF}_{6}{ }^{-}$counter ion, the cavity of $C D$ of 12 is undoubtedly available.

From these preliminary results, we focused our study on CD-LI+PSS ${ }^{-} 13$, and its precursors $\beta-C D, 10$ and 11, all water-soluble. The pink PP solution has a maximum of absorption at $553 \mathrm{~nm}$ which became colorless in presence of all CD derivatives proving the inclusion phenomena. As expected, the absorbance of PP decreased with the increase of concentration $(1,5,10,20$ et 25 equivalents) of host molecules $\beta$-CD, CD-NH 2 10, CD-IL ${ }^{+} \mathrm{Br}^{-} 11$ et CD-IL ${ }^{+}$PSS $^{-} 13$ following the Beer-Lambert rule (Table 4) (Eftink and Harrison 1981; Wang and Song 2007; Khalafi and Rafiee 2013). The chemical modifications on the CD rim did not change the inclusion properties. Indeed, similar results were obtained for $\beta-C D, 10$, and 11. The weak decrease observed with $\mathbf{1 3}$ could be due to steric hindrance induced by the polymeric structure. 
Table 4

Percentage of inclusion of PP in CDs

\begin{tabular}{|lllll|}
\hline Equivalent of $\mathbf{C D}$ & $\boldsymbol{\beta}-\mathrm{CD}$ & $\mathbf{C D}-\mathrm{NH}_{\mathbf{2}} \mathbf{1 0}$ & $\mathrm{CD}^{-\mathrm{IL}^{+} \mathrm{Br}^{-} \mathbf{1 1}}$ & $\mathrm{CD}^{-\mathrm{IL}^{+} P S S^{-}{ }^{-13}}$ \\
\hline 1 & $70 \%$ & $65 \%$ & $62 \%$ & $66 \%$ \\
\hline 5 & $90 \%$ & $85 \%$ & $87 \%$ & $82 \%$ \\
\hline 10 & $93 \%$ & $92 \%$ & $93 \%$ & $86 \%$ \\
\hline 20 & $94 \%$ & - & $93 \%$ & $88 \%$ \\
\hline 25 & $97 \%$ & $96 \%$ & $96 \%$ & $88 \%$ \\
\hline$* 1 / 25$ CD-IL/SS experimental ratio & & $89 \%$ \\
\hline
\end{tabular}

$82 \%$ And $90 \%$ of PP were encapsulated in the CD-IL ${ }^{+} P S S^{-13}$ and in $\beta$-CD in presence of 5 equivalents of $C D$ units, respectively. This weak decrease could be due to steric hindrance induced by the polymeric structure. The absence of variation of percentage of inclusion between CD-NH 10 and $\mathrm{CD}-\mathrm{IL}^{+} \mathrm{Br}^{-} 11$ (65\% and $62 \%$, respectively, Table 4) supports the idea of no competition between the IL linker and the guest.

The monosubstitution on the primary face of the $\beta$-CD did not interfere with the formation of the inclusion complexes. The short ionic linker grafted on the $C D$ rim reduces its mobility and limits the inclusion of the IL unit into the cavity (intramolecular inclusion). Besides, the low concentration used during the immobilization on PSS does not favor the interaction between the IL unit and another CD cavity (intermolecular inclusion). Consequently, the inclusion efficiency corresponds to direct accessibility of the $C D$ site, and a perhydroxylated $\beta-C D$ is required to form supramolecular complexes.

The influence of the IL immobilized on the rim of $\beta$-CD on its complexation ability was studied via the inclusion of $p$-nitrophenol (PNP pKa 7.04) as a model by UV-visible spectroscopy (Tagushi 1986; Gelb et al. 1995). This experiment was performed with the protonated form of $p$-nitrophenol. A molar extinction coefficient of $18801 \mathrm{~L} . \mathrm{mol}^{-1} . \mathrm{cm}^{-1}$ at $400 \mathrm{~nm}$ was confirmed in presence of $\beta$-CD. The Job plot experiment also confirmed the 1:1 $\beta$-CD/PNP stœechiometry. The study was then carried out with 0 to $1.5 \mathrm{mmol} / \mathrm{L}$ of $\mathrm{CD}-\mathrm{IL}^{+} \mathrm{Br}-11$ (0 to 30 equivalents) and an association constant of $\mathrm{Ks}=200 \mathrm{M}^{-1}$ was calculated with a negative standard free enthalpy $\Delta \mathrm{rG}^{\circ}{ }_{\text {exp }}=-13.2 \mathrm{KJ} / \mathrm{mol} .+$

2-Anilino-6-naphtalene sulfonate (2,6-ANS) is a polar sensitive fluorescent probe towards their local environment (Eftink and Harrison 1981; Wang and Song 2007; Khalafi and Rafiee 2013). The fluorescent properties decrease with the increase of polarity such as in water and are applied for host-guest inclusion complexes with cyclodextrins. The fluorescence intensity of 2,6-ANS increased with the addition of the four $C D$ derivatives $(\beta-C D, 10,11$, and 13 with grafting rate of $1 / 25 C D / S S$ ) attesting of inclusion complex phenomena (for 13, Fig. 11). Indeed maximal wavelengths $\lambda_{F, m a x}$ at $467 \mathrm{~nm}$ in absence of $C D$ at $2 \mathrm{mM}$ 
shifted, respectively, of $20,42,23$, and $20 \mathrm{~nm}$ in presence of $\beta$-CD, 10, 11, and 13 confirming the absence of modification of inclusion properties of the modified CDs.

The fit of the fluorescent titration ratio F/Fo obtained depends on the CD derivative concentration provided association constant Ks; a maximal value corresponding to $100 \%$ of inclusion (Eq. 1-3, Table 5). Higher values of Ks indicate a higher affinity of ANS for CD because of a more apolar cavity (Favrelle et al. 2015)

$$
\mathrm{CD}+\mathrm{ANS} \leftrightarrow \mathrm{CD}: \mathrm{ANS}(1) \quad \mathrm{Ks}=\frac{[\mathrm{CD}: \mathrm{ANS}]}{[\mathrm{CD}] \times[\mathrm{ANS}]} \quad(2) \quad \mathrm{F} / \mathrm{Fo}_{0}=1+(\mathrm{F} \infty / \mathrm{Fo}-1) \frac{[\mathrm{CD}] \cdot \mathrm{Ks}}{(1+[\mathrm{CD}] \cdot \mathrm{Ks})}
$$

F: Integrated area of the fluorescence spectrum; Fo: Total fluorescence intensity in the absence of CD; Fo: Maximum fluorescence enhancement

In presence of 2,6-ANS, CD-IL ${ }^{+} P S S^{-} 13$ (with grafting ratio $1 / 20 \mathrm{CD} / \mathrm{SS}$ ) generated the higher $\mathrm{F} / \mathrm{F}_{0}$ value, due to the higher affinity of the hydrophobic part of guest for CD cavity (Table 5). The influence of grafting rate (1/25 and 1/20 CD/SS) on the inclusion of 2,6-ANS has been studied (Table 5).

Table 5

Fluorescent titration and association constants of 2,6-ANS inclusion complex in CDs

\begin{tabular}{|c|c|c|c|}
\hline CD & CD-IL/SS & $\mathrm{F}_{\max } / \mathrm{F}_{0}^{\mathrm{a}}$ & $\mathrm{Ks}\left(\mathrm{M}^{-1}\right)$ \\
\hline$\beta-C D$ & - & 8.90 & $3,360 \pm 720$ \\
\hline CD-NH ${ }_{2} 10$ & - & 11.02 & $2,210 \pm 450$ \\
\hline CD-IL'Br ${ }^{+} 11$ & - & 12.41 & $3,350 \pm 430$ \\
\hline CD-IL ${ }^{+}$PSS $^{-13}$ & $1 / 25$ & 13.82 & $9,550 \pm 500$ \\
\hline CD-IL ${ }^{+}$SSS $^{-13}$ & $1 / 20$ & 14.38 & $11,070 \pm 860$ \\
\hline
\end{tabular}

High association constants were observed in both cases underlying the weak influence of the grafting efficiency in the range studied (1/25 and 1/20, Table 5$)$. Consequently, the ionic PSS has a positive and significant impact on inclusion properties, with a factor of 2.9 and 3.3 on Ks values for CD-IL ${ }^{+} \mathrm{PSS}^{-} 13$ with $1 / 25$ and $1 / 20$ ratio respectively, by comparison with $\mathrm{CD}^{-} \mathrm{IL}^{-} \mathrm{Br}^{+} \mathbf{1 1}$.

In both cases, the cavities of CDs were accessible in a similar manner confirming the absence of intermolecular interaction between the IL linker and another CD cavity. The reciprocal curve $1 /(\mathrm{F} / \mathrm{Fo}-1)$ in function of $1 /[C D]$ is representative of the stœchiometry of the 2,6-ANS/CD complex (Eq. 4) (Favrelle et al. 2015). 
$1 /((\mathrm{F} / \mathrm{Fo}-1))=(1 /[\mathrm{CD}])$

In presence of 1 equivalent of host $C D$ linear plots $\left(R^{2}=0.997\right)$ were observed with 13 for both grafting rate (1/25 and $1 / 20 \mathrm{CD} / \mathrm{SS})$ validating the $1: 1$ stœechiometry (Fig. 12).

\section{Dialysis Pore Water Sampler Development}

The accurate knowledge of the pollution level in pore-water sediment is a challenge for geologists. The literature on the porewater sampling methods is based on two different approaches. The first one is at a laboratory scale and requires sediment cores that are cut into several centimeter fractions. Then, the porewater is extracted by centrifugation under nitrogen squeeze (Bufflap and Allen 1995; Brinkman et al. 1982). This method requires physical pressures onto sediments and overestimates the nutrient concentrations by desorbing the ions fixed onto the particles. The second one is based on an in-situ approach which uses dialyzer devices that are introduced in the sediment in which the pores are filled after an equilibration time at the sediment water interface. The main strategies of pore-water sampling are dialysis (Hesslein 1976), DET (Diffusive equilibration in thin films, Davison et al. 2000) and DGT (Diffusive gradients in thin films, Zang and Davison 1995).

The support obtained found an application in a dialysis porewater sampler, type Hesslein, to extract and release pollutants from sediment in the long-term (Fig. 13C). This dialyzer is commonly used in geology studies to identify the pollutant concentration in the various layers of estuaries sediment by studying the interstitial water according to a continuous gradient between the sediment and the water column over 30 cm height (Bally et al. 2004, 2005; Mesnage et al. 2007, 2013). The nutrient concentrations gradients led to nutrients fluxes calculation via a numerical diffusion model at the sediment-water interface. The main disadvantage compared to other methods (DGT or DET, Zang and Davison, 1995) is its long equilibration time (20 days related to the sediment type).

Owing to this ternary water-soluble support, the organic pollutants could be extracted, concentrated, and analyzed under their organic forms. Moreover, the presence of the support should modify the equilibrium time, and consequently reduce the collection time of the estuaries water samples. To test the efficiency of the technique, the water-soluble quencher was introduced into the cavities of the dialyzer and 2,6-ANS was used as a pollutant model (Fig. 13A and B). A specific membrane based on polysulfone was used to avoid biodegradation during the dialysis by the bioorganisms present in the sediment. The dialyzer was used in the presence of $2 \mathrm{mM}$ of 2,6-ANS water solution and stoichiometric CD-LI+ PSS $^{-} 13$.

After non-optimized equilibration time (8 hours), each cell was extracted and the presence of 2,6-ANS was confirmed by UV-Visible spectroscopy. In-situ, in presence of sediment, an equilibration time of 3 weeks is usually needed. The samples were collected and analyzed by NMR spectrometry. A slight shift was detected between 2,6-ANS with and without CD-LI+PSS- 13. NOESY experiment showed the interaction between the aromatic group of 2,6-ANS and $\mathrm{H} 3$ and $\mathrm{H} 5$ of the internal cavity of the cyclodextrin proving the formation of an inclusion complex and the absence of free 2,6-ANS. + Similar experiments in presence of PSS $\mathrm{Na}^{+}$or $\mathrm{CD}-\mathrm{LI}^{+} \mathrm{Br}^{-} 11$ could not be efficient because of the absence of anion interactions with the 
polymer or the diffusion of $\mathrm{CD}-\mathrm{LI}^{+} \mathrm{PF}_{6}{ }^{-} \mathbf{1 3}$ through the dialysis membrane. After validation of the extraction capacity of the support in dialyzer conditions, a liquid/liquid extraction led to the pollutant model and regenerated after lyophilization the free support CD-Li ${ }^{+} \mathrm{PSS}-13$, ready for a new use. ${ }^{1} \mathrm{H}$ NMR analysis confirmed the decomplexation step (13 et 2,6-ANS). The 2,6-ANS was recovered quantitatively attesting the future potential of this application.

\section{Conclusion}

Two new ternary complexes $\mathrm{CD}(\mathrm{OMe})-\mathrm{IL}^{+} \mathrm{PSS}-\mathrm{and}^{\mathrm{C}} \mathrm{CD}-\mathrm{IL}^{+} \mathrm{PSS}^{-}$were obtained by simple dialysis with a maximal CD/SS grafting rate of $25 \%(1 / 4)$ and $20 \%(1 / 5)$, respectively. The precursor can be easily synthesized in two steps in $77 \%$ global yield. The ionic binding between an ionic polymer and a cationic ionic liquid was proved by NMR spectroscopies. The immobilization of CD-IL on polymer PSS was measured by SEC/MALS/DRI analysis. The permethylated CD derivatives showed a weak capacity for complexation. The properties of inclusion of the polyelectrolytes and their CDs precursors were studied by UV-visible, fluorescent, and NMR spectroscopies using three reference guests and compared with the properties of the native $\beta-C D$. The immobilization of a short ionic linker on $\beta$-cyclodextrin inhibited all intramolecular inclusion phenomena and provided certain flexibility to improve the electrostatic interactions with PSS. This strategy left free the hydrophobic cavities of CD for a complexation. The monosubstitution of hydroxylated $\mathrm{CD}$ by an ionic liquid supported by an anionic polymer has a positive effect on the ability of host-guest inclusion. The higher retention of guests is due to the synergy between the polymeric matrix and the cyclodextrin cavity. Finally, a higher grafting generated the higher complexation abilities proving the absence of intermolecular interactions and the absence of steric hindrance of the polymeric matrix. In perspective, this new water-soluble ternary complex CD-IL ${ }^{+} \mathrm{PSS}^{-}$ could be an interesting tool for water dialysis device. In presence of dialysis membrane, this captor is an alternative to adsorption purification techniques (sand filter, activated charcoal, exchange of ions) and could be kinetically more efficient due to the presence of a the homogeneous medium. Polluting molecules could be faster preconcentrated in a fluid environment. This simple and flexible synthetic strategy opens the way to new hybrid materials with great potential. Complementary tests in presence of solution sediment suspended are in progress in collaboration with a geology laboratory to reach a gradient concentration of organic pollutants in shorter equilibrium time. Then, the optimized device will be applied in temperate zone of the Seine Estuary (France) and in tropical zone of the Somone Estuary (Senegal).

\section{Declarations}

\section{Acknowledgments}

We thank the European Union for their financial support in the purchase of equipment. We thank Christophe Rihouey from PBS laboratory for the chromatography analysis. We are also grateful for the compagny Cyclolab, https://cyclolab.hu/, for its contribution by sending $\beta$-CD-NH 10 . 
Authors'contribution Conceptualization, G.G. and D.L.; Methodology, G.G, D.L., C.K-D., F.G., V.M. and M.L.; Validation, G.G, D.L., C.K-D., F.G., V.M.; Formal Analysis, A.B., S.B., A.F-H., F.G., B.S.S.B. and C.K-D.; Investigation, A.B., S.B., A.F.-H., F.G., B.S.S.B. and C.K-D.; Writing-Original draft preparation G.G.; Writingreview and editing, G.G., D.L, M.L. F.G, V.M. and C.K.-D. Supervision, G.G, D.L., C.K-D., F.G. and M.L.; Project administration, Funding acquisition, G.G., M.L. and D.L.

Funding This work was supported by « le Conseil Régional de Haute-Normandie » and « l'Institut Normand de Chimie Moléculaire, Macromoléculaire et Médicinale » INC3M, FR 3038 CNRS (A.F.-H.). We are grateful to Erasmus Mundus program Battuta for the fellowship (A.B.), the CNRS/CNRST international program (A.B.) and the MRT for their financial supports (B.S.S.B).

Data availability All data generated or analyzed during this study are included in this published article. Supplementary Materials is represented by the symbol † in the text. The materials, method, synthesis and characterization details of products $2,3,4,7,9,11,1213$ are available online. Graphs of $p$-nitrophenol inclusion study (absorbance and job plot, stability constants table), and NOESY NMR of inclusion complex of 13:2,6-ANS obtained with the dialyzer were also reported.

Competing interests The authors declare that they have no conflict of interest.

Ethics approval The authors confirm that the manuscript has been read and approved by all authors and not under consideration for publication elsewhere.

Consent to participate The authors have been personally and actively involved in substantive work leading to the manuscript and will hold themselves jointly and individually responsible for its content.

Consent for publication The authors consent to publish this research.

\section{References}

Amiel C, Galant C, Auvray L (2004) Ternary complexes involving a b-cyclodextrin polymer, a cationic surfactant and an anionic polymer. Prog Colloid Polym Sci 126:44-46. https://doi.10.1007/b93967

Anderson JL, Clark KD (2018) Ionic liquids as tunable materials in (bio)analytical chemistry. Ana Bioanal Chem 410:4565-4566. https://doi.10.1007/s00216-018-1125-4

Antoniuk I, Amiel C (2016) Cyclodextrin-mediated hierarchical self-assembly and its potential in drug delivery applications. J Pharm Sci 1-19. https://doi.org/10.1016/j.xphs.2016.05.010

Badruddoza AZ, Bhattarai B, Suri RPS (2017) Environmentally friendly b-cyclodextrin-ionic liquid polyurethane-modified magnetic sorbent for the removal of PFOA, PFOS, and $\mathrm{Cr}(\mathrm{VI})$ from water. ACS Sustainable Chem Eng 5:9223-9232. https://doi.org/10.1021/acssuschemeng.7b02186

Bahadorikhalili S, Ansari S, Hamedifar H, Mahdavi M (2019) The use of magnetic starch as a support for an ionic liquid-b-cyclodextrin based catalyst for the synthesis of imidazothiadiazolamine derivatives. Int $J$ 
Biological Macromol 135:453-461. https://doi.org/10.1016/j.ijbiomac.2019.05.197

Bakheet AAA, Liu J, Zhu X (2016) New magnetic solid phase extractor based on ionic liquid modified $\beta$ cyclodextrin polymer/ $\mathrm{Fe}_{3} \mathrm{O}_{4}$ nanocomposites for selective separation and determination of Linuron. $\mathrm{J}$ Anal Sc. Techn 7:1-10. https://doi.10.1186/s40543-016-0082-9

Bakheet AAA and Zhu XS (2017) Determination of rhodamine B in food samples by $\mathrm{Fe}_{3} \mathrm{O}_{4} @$ @ionic liquids$\beta$-cyclodextrin cross linked polymer solid phase extraction coupled with fluorescence spectrophotometry. J Fluoresc 27:1087-1094. https://doi.10.1007/s10895-017-2042-1

Bally G, Mesnage V, Deloffre J, Clarisse O, Lafite R, Dupont J-P (2004) Chemical characterization of porewaters in an intertidal mudflat of the Seine estuary: relationship with erosion-deposition cycles. Marine Pollution Bulletin 49:163-173. https://doi.10.1016/j.marpolbul.2004.02.005

Bally G, Mesnage V, Verney R, Clarisse O, Dupont J-P, Ouddanne B, Lafite R (2005) Exchange and release processes dialysis porewater sampler: a strategy for time equilibration optimization. In: Seranno, L., Golterman, H.L. (Eds.), Phosphates in Sediments, Proceedings of the 4th International Symposium. Backhuys, The Netherlands, 9-20.

Barhoumi Z, Saini M, Amdouni N, Pal A (2016) Interaction between amphiphilic ionic liquid 1-butyl-3methylimidazolium octyl sulfate and anionic polymer of sodium polystyrene sulfonate in aqueous medium. Chem Phys Lett 661:173-178. https://doi.org/10.1016/j.cplett.2016.08.016

Brinkman A, Van Raasphorst W, Lijklema L (1982) In situ sampling of interstitial water from lake sediments. Hydrobiologia 92:659-663. https://doi.org/10.1007/BF00000065

Bufflap SE and Allen HE (1995) Sediment pore water collection methods for trace metal analysis: A review. Water Resour. 29:165-177. https://doi.org/10.1016/0043-1354(94)E0105-F

Cyclolab, Compounds $\mathbf{8}$ and $\mathbf{1 0}$ are also commercially available:

https://cyclolab.hu/products/cationic_cyclodextrins-c18.

Davison W, Fones GR, Harper M, Teasdale P, Zhang H (2000) Dialysis, DET and DGT: in situ diffusional techniques for studying water, sediments and soil. In: Buffle J, Horvai G, editors. In-situ monitoring of aquatic systems: chemical analysis and speciation. IUPAC. England: John Wiley \& Sons Ltd; 495-569.

D’Souza VT (1998) Cyclodextrins. Chem Rev 98:1741-2076. https://doi.10.1021/cr980027p

Eftink MR, Harrison JC (1981) Calorimetric studies of $p$-nitrophenol binding to a- and b-cyclodextrin. BioOrg Chem 10:388-398. https://doi.org/10.1016/0045-2068(81)90051-1

Favrelle A, Gouhier G, Guillen F, Martin C, Mofaddel N, Mundy K, Pitre S, Wagner B (2015)

Structure-binding effects: comparative binding of 2-anilino-6-naphthalenesulfonate by a series of alkyl- 
and hydroxyalkyl-substituted $\beta$-cyclodextrins. J Phys Chem B 119:12921-12930. https://doi.10.1021/acs.jpcb.5b07157

Galant C, Amiel C. Tailorable polyelectrolyte complexes using cyclodextrin polymers (2004) J. Phys. Chem. B. 108:19218-19227. https://doi.org/10.1021/jp047494x

Gao Q, Liu W, Zhu X (2020) Glycine ionic liquid functionalized b-cyclodextrin polymer high-performance liquid chromatography for the separation/analysis of pyrethroids. J Liquid Chromat Related Tech 809818. https://doi.org/10.1080/10826076.2020.1816550

Gelb RI, Raso S, Alper JS (1995) Complexation reactions of $\beta$-cyclodextrin, per-(2,3,6-O-methyl) cycloheptaamylose and $\gamma$-cyclodextrin with phenolphthalein, adamantane carboxylate and adamantane acetate. Supramol Chem 4:279-285. https://doi.org/10.1080/10610279508028937

Hallett JP, Welton T. (2011) Room-temperature ionic liquids: solvents for synthesis and catalysis. Chem Rev 111:3508-3576. https://doi.org/10.1021/cr1003248

Hayes R, Warr GG, Atkin R. (2015) Structure and nanostructure in ionic liquids. Chem Rev 115:6357-6426. https://doi.org/10.1021/cr500411q

Hesslein R H (1976) An in situ sampler for close interval pore water studies. Limnology \& Oceanography 21:912-914. https://doi.org/10.4319/lo.1976.21.6.0912

Jiao Y, Chou T, Akcora P (2015) Design of ion-containing polymer-grafted nanoparticles for conductive membranes. Macromol 48:4910-4917. https://doi.org/10.1021/acs.macromol.5b00758

Jicsinszky L, Caporaso M, Tuza K, Martina K, Gaudino EC, Cravotto G (2016) Nucleophilic substitutions of 6I-O-monotosyl- $\beta$-cyclodextrin in a planetary ball mill. ACS Sustainable Chem Eng 4:919-929. https://doi.org/10.1021/acssuschemeng.5b01006

Khalafi L, Rafiee M (2013) Cyclodextrin based spectral changes. Intech chapter 19:472-493. https://doi.10.5772/52824

Kissoudi M, Samanidou V (2018) Recent advances in applications of ionic liquids in miniaturized microextraction techniques. Molecules 23:1437-1449. https://doi.10.3390/molecules23061437

Koel M (2016) Analytical application of ionic liquids. World Scientific 1-438. https://doi.org/10.1142/q0021

Li J, Wang X, Duan H, Wang Y, Bu Y, Luo C (2016) Based on magnetic graphene oxide highly sensitive and selective imprinted sensor for determination of sunset yellow. Talanta 147:169-176. https://doi.org/10.1016/j.talanta.2015.09.056 
Mahlambi MM, Malefeste TJ, Mamba BB, Krause RW (2010) $\beta$-Cyclodextrin-ionic liquid polyurethanes for the removal of organic pollutants and heavy metals from water: synthesis and characterization. $\mathrm{J}$ Polym Res 17:589-600. https://doi.10.1002/jctb.1681

Mahlambi MM, Malefeste TJ, Mamba BB, Krause RW (2011) lonic Liquids: Applications and Perspectives. InTech, Chapter 7. https://doi.10.5772/1782

Mesnage V, Ogier S, Bally G, Disnar J-R, Lottier N, Dedieu K, Rabouille C, Copard Y (2007) Nutrient dynamics at the sediment-water interface in a Mediterranean lagoon (Thau, France): Influence of biodeposition by shellfish farming activities. Marine Environmental Research 63:257-277. https://doi.org/10.1016/j.marenvres.2006.10.001

Mesnage V, Lecoq N, Sakho I, Vennin A (2013) Modelling nutrients fluxes at the sediment-water interface in two contrasted climate estuaries: Seine estuary (France) and Somone (Senegal). Compte-Rendu Géosciences. 345:439-445. https://doi.org/10.1016/j.crte.2013.11.003

Mincheva Z, Bonnette F, Lavastre $O$ (2007) Ionic liquid supports stable under conditions of peptide couplings, deprotections and traceless Suzuki reactions. Coll Czech Chem Commun 72:417-434. https://doi.10.1135/cccc20070417

Mofaddel N, Fourmentin S, Guillen F, Landy D, Gouhier G (2016) lonic liquids and cyclodextrin inclusion complexes: limitation of the affinity capillary electrophoresis technique. Anal Bioanal Chem 408:82118220. https://doi.10.1007/s00216-016-9931-z

Mohamad S, Chandrasekaram K, Rasdi FLM, Manan NSA, Raoov M, Sidek N, Fathullah SF (2015) Supramolecular interaction of 2,4-dichlorophenol and $\beta$-cyclodextrin functionalized ionic liquid and its preliminary study in sensor application. J Mol Liquids 212:850-856.

https://doi.org/10.1016/j.molliq.2015.10.044

Moutard S, Perly B, Godé P, Demailly G, Djedaïni-Pilard F (2002) Novel glucolipids based on cyclodextrins. J Inclusion Phen Macrocyc Chem 44:317-322. https://doi.10.1023/A:1023014718447

Nielsen TT, Wintgens V, Amiel C, Wimmer R, Larsen KL (2010) Facile synthesis of b-cyclodextrin-dextran polymers by "click" chemistry. Biomacromolecules 11:1710-1715. https://doi.org/10.1021/bm9013233

Pandey S (2006) Analytical applications of room-temperature ionic liquids: A review of recent efforts. Anal Chimica Acta 556:38-45. https://doi.org/10.1016/j.aca.2005.06.038

Qin X, Zhu X (2017) lonic liquid-b-cyclodextrin polymer for the separation/analysis of iornoxicam. Supramol. Chem. 29:205-214. https://doi.org/10.1080/10610278.2016.1202411

Quin X, Chen S, Gu W, Zhu X (2016) Speciation analysis of Mn(II)/Mn(IV) using $\mathrm{Fe}_{3} \mathrm{O}_{4} @$ ionic liquid-bcyclodextrin polymer magnetic solid phase extraction coupled with ICP-OES. Talanta 161:325-332. 
Rahim NY, Tay KS, Mohamad S (2016a) b-Cyclodextrin functionalized ionic liquid as chiral stationary phase of high performance liquid chromatography for enantioseparation of b-blockers. $\mathrm{J}$ Incl Phenom Macrocycl Chem 85:303-315. https://doi.10.1007/s10847-016-0629-9

Rahim NY, Tay KS, Mohamad S (2016b) Chromatographic and spectroscopic studies on $\beta$-cyclodextrin functionalized ionic liquid as chiral stationary phase: enantioseparation of flavonoids. Chromatographia 79:1445-1455. https://doi.org/10.1177/0263617416686798

Raoov M, Mohamad S, Abas MR (2013) Removal of 2,4-dichlorophenol using cyclodextrin-ionic liquid polymer as a macroporous material: Characterization, adsorption isotherm, kinetic study, thermodynamics. J Hazardous Mat 263:501-516. https://doi.org/10.1016/j.jhazmat.2013.10.003

Raoov M, Mohamad S, Abas MR (2014a) Synthesis and characterization of $\beta$-cyclodextrin functionalized ionic liquid polymer as a macroporous material for the removal of phenols and As(V). Int J Mol Sci 15:100-119. https://doi.10.3390/ijms15010100.

Raoov M, Mohamed S, Abas MR, Surikumaran H (2014b) New macroporous b-cyclodextrin functionalized ionic liquid polymer as an adsorbent for solid phase extraction with phenols. Talanta 130:155-163. https://doi.10.1016/j.talanta.2014.06.067

Rasdi FLM, Mohamad S, Manan NSA, Nodeh HR (2016) Electrochemical determination of 2,4dichlorophenol at b-cyclodextrin functionalized ionic liquid modified chemical sensor: voltammetric and amperometric studies. RSC Adv 6:100186-100194. https://doi.10.1039/c6ra19816c

Rogalski M, Modaressi A, Magri P, Mutelet F, Grydziuszko A, Wlazło M, Domańska U (2013) Cloud point extraction of parabens using non-ionic surfactant with cyclodextrin functionalized ionic liquid as a modifier. Int J Mol Sci 14:16638-16655. https://doi.10.3390/ijms141224531.

Sinniah S, Mohamad S, Manan NSA (2015) Magnetite nanoparticles coated with b-cyclodextrin functionalized-ionic liquid: Synthesis and its preliminary investigation as a new sensing material. App Surface Sci 357:543-550. https://doi.org/10.1016/j.apsusc.2015.09.078

Taguchi K (1986) Transient binding mode of phenolphthalein-b-cyclodextrin complex: an example of induced geometrical distortion. J Am Chem Soc 108:2705-2709. https://doi.org/10.1021/ja00270a032

Tang W, Ng SC (2008) Facile synthesis of mono-6-amino-6-deoxy-a-,b,-g-cyclodextrin hydrochlorides for molecular recognition, chiral separation and drug delivery. Nature Protocols 3:691-697. https://doi.

10.1038/nprot.2008.37

Wagner B, Fitzpatrick SJ (2000) A Comparison of the host-guest inclusion complexes of 1,8-ANS and 2,6-ANS in parent and modified cyclodextrins. J Incl Phenom Macrocyclic Chem 38:467-478. https://doi. 10.1023/A:1008198825835 
Wang HM, Song LX (2007) A good linear relationship between the logarithms of formation constants and the stabilization energies of a- and b-cyclodextrin complexes of several phenol and benzoic derivatives. Chem Lett 36:596-597. https://doi.org/10.1246/cl.2007.596

Wu X, Yang M, Zeng H, Xi X, Zhang S, Lu R, Gao H, Zhou W (2016) Effervescence-assisted dispersive solid-phase extraction using ionic-liquid-modified magnetic b-cyclodextrin/attapulgite coupled with highperformance liquid chromatography for fungicide detection in honey and juice. J Sep Sci 1-7. https://doi.10.1002/jssc.201600596

Yang M, Xi X, Wu X, Lu R, Zhou W, Zhang S, Gao H (2015) Vortex-assisted magnetic bcyclodextrin/attapulgite-linked ionic liquid dispersive liquid-liquid microextraction coupled with highperformance liquid chromatography for the fast determination of four fungicides in water samples. $J$ Chromatogr A 1381:37-47. https://doi.org/10.1016/j.chroma.2015.01.016

Yusoff MM, Raoov M, Yahaya N, Salleh NM (2017) An ionic liquid loaded magnetically confined polymeric mesoporous adsorbent for extraction of parabens from environmental and cosmetic samples. RSC Adv 7:35832-35844. https://doi.org/10.1039/C7RA06682A

Zhang $\mathrm{H}$ and Davison W (1995) Performance characteristics of diffusion gradients in thin-films for the insitu measurement of trace metals in aqueous solutions. Analytica Chemistry 67:3391-3400. https://doi.org/10.1021/ac00115a005

Zhang LX, Liu T, Luo AQ (2011) Application of quaternary aminated $\beta$-cyclodextrin ionic liquid stationary phase in capillary gas chromatography. Adv Mater Res 317-319:1936-1939.

https://doi.org/10.4028/www.scientific.net/AMR.317-319.1936

Zhao F, Xiao F, Zeng B (2010) Electrodeposition of PtCo alloy nanoparticles on inclusion complex film of functionalized cyclodextrin-ionic liquid and their application in glucose sensing. ElectroChem Commun 12:168-171. https://doi.org/10.1016/j.elecom.2009.11.016

Zhou C, Deng J, Shi G, Zhou T (2017) b-cyclodextrin-ionic liquid polymer based dynamically coating for simultaneous determination of tetracyclines by capillary electrophoresis. Electrophoresis 38:1060-1067. https://doi.10.1002/elps.201600229

Zhou N, Zhu XS (2014) Ionic liquids functionalized $\beta$-cyclodextrin polymer for separation/analysis of magnolol. J Pharm Anal 4:242-249. https://doi.10.1016/j.jpha.2013.12.005

\section{Figures}



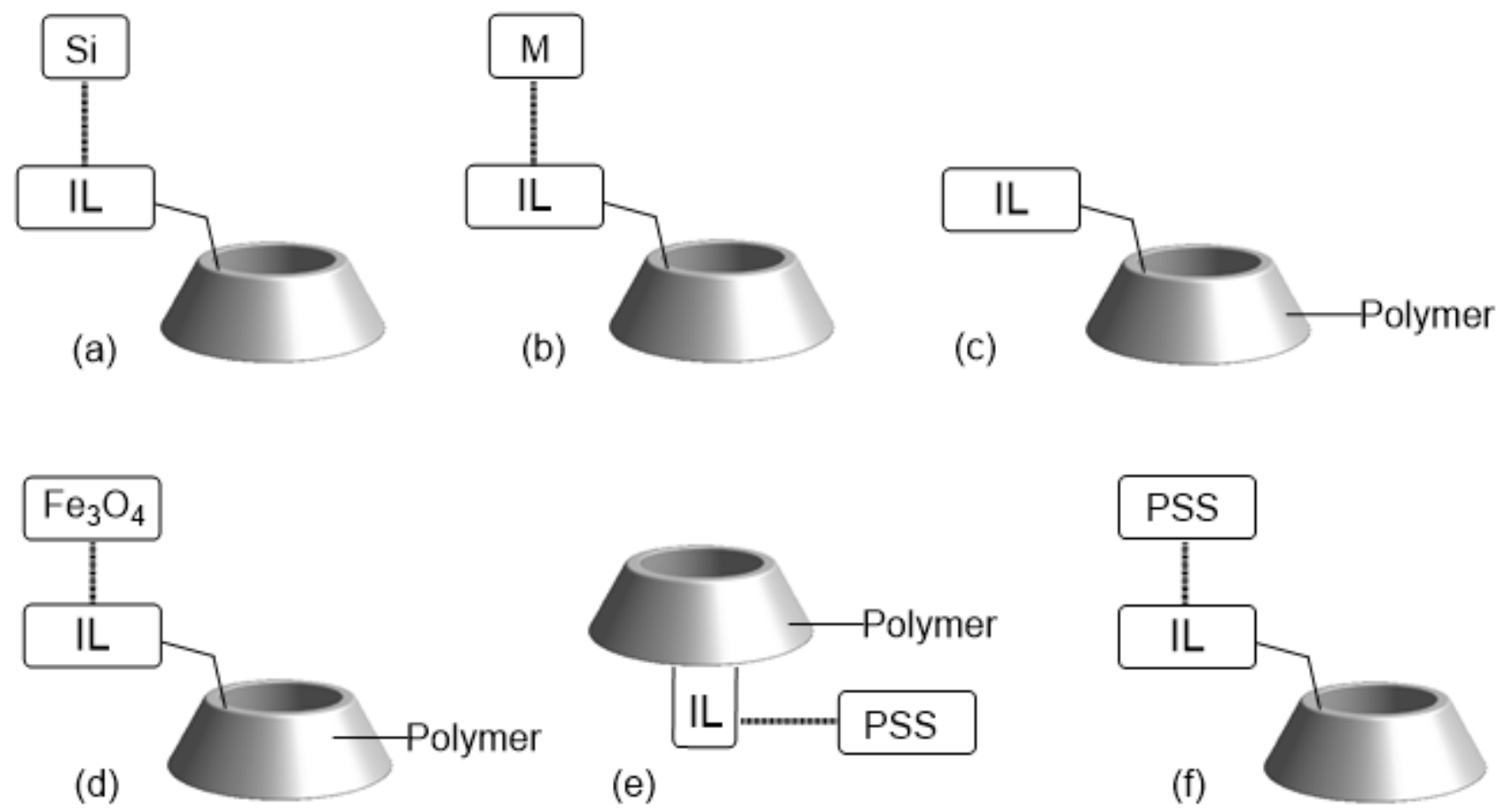

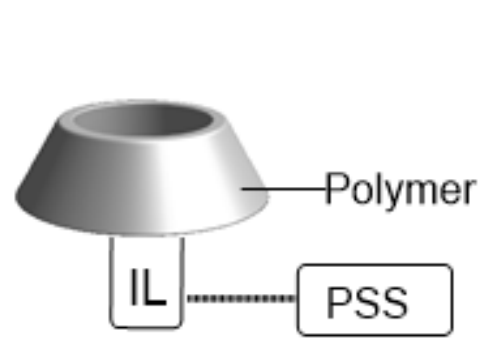

(e)

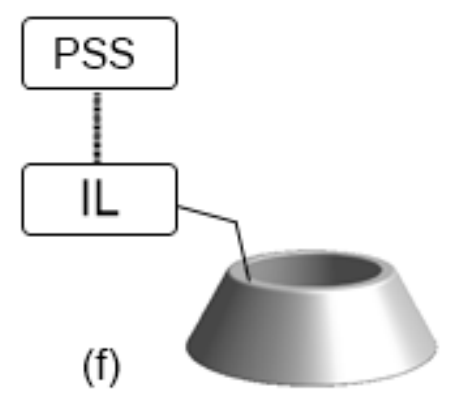

Figure 1

Tripartite associations between cyclodextrin, ionic liquid (IL) and supports: published (a, b, c, d, e), this work (f). M=Metal, Si: silica, PSS: poly(styrene sulfonate)

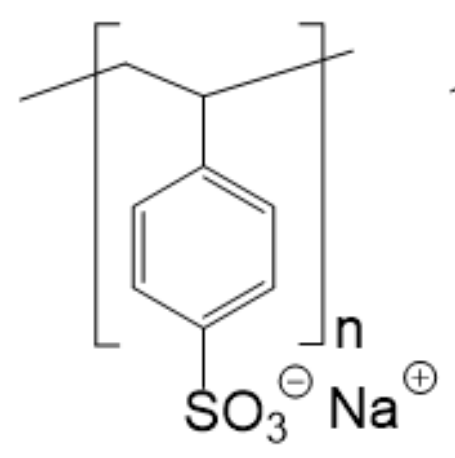

PSS

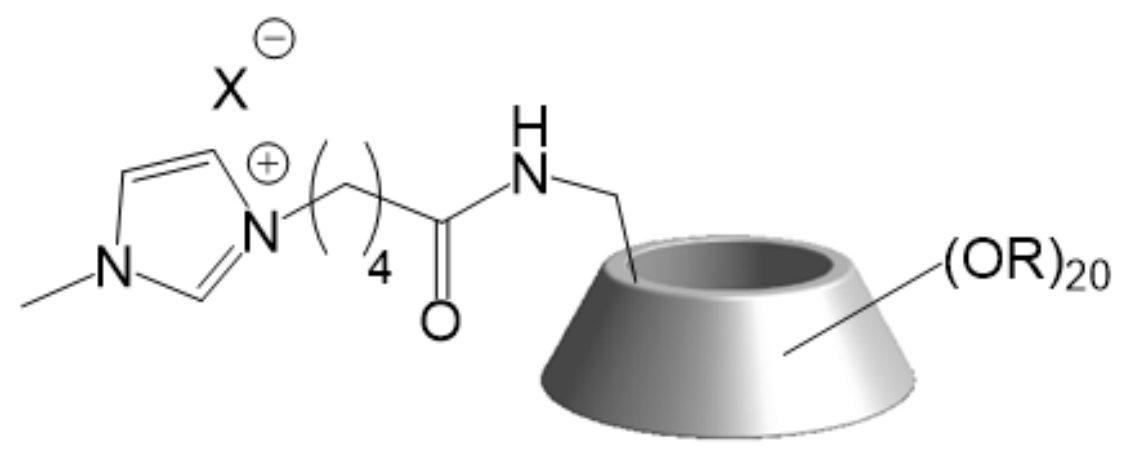

CD-IL

$\mathrm{R}=\mathrm{H}$

$\mathrm{R}=\mathrm{Me}$

\section{Figure 2}

Immobilization of cyclodextrin-ionic liquid (CD-IL) on poly(styrene sulfonate) (PSS) 


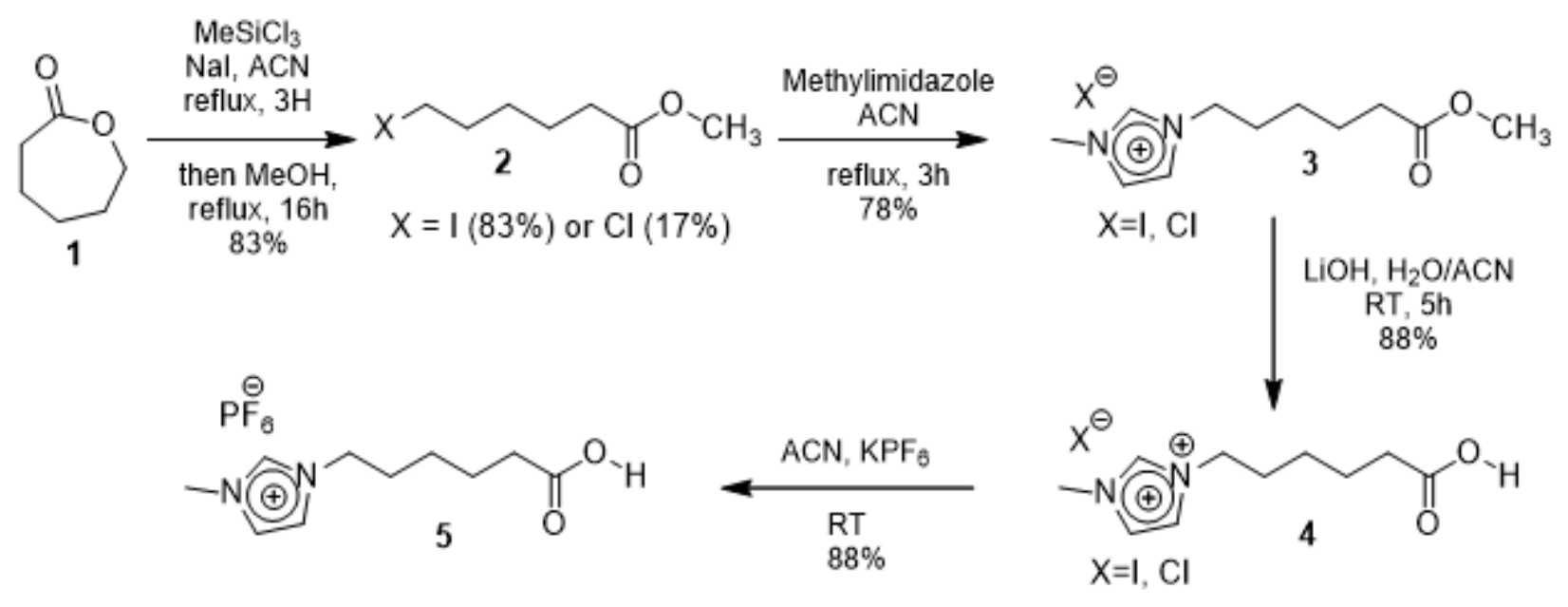

Figure 3

Synthesis of ionic liquid precursor 5

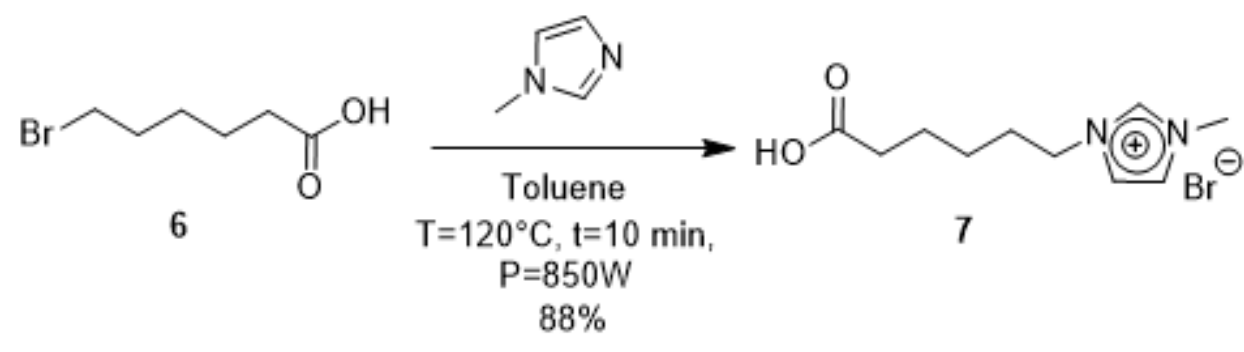

Figure 4

Synthesis of ionic liquid precursor 7

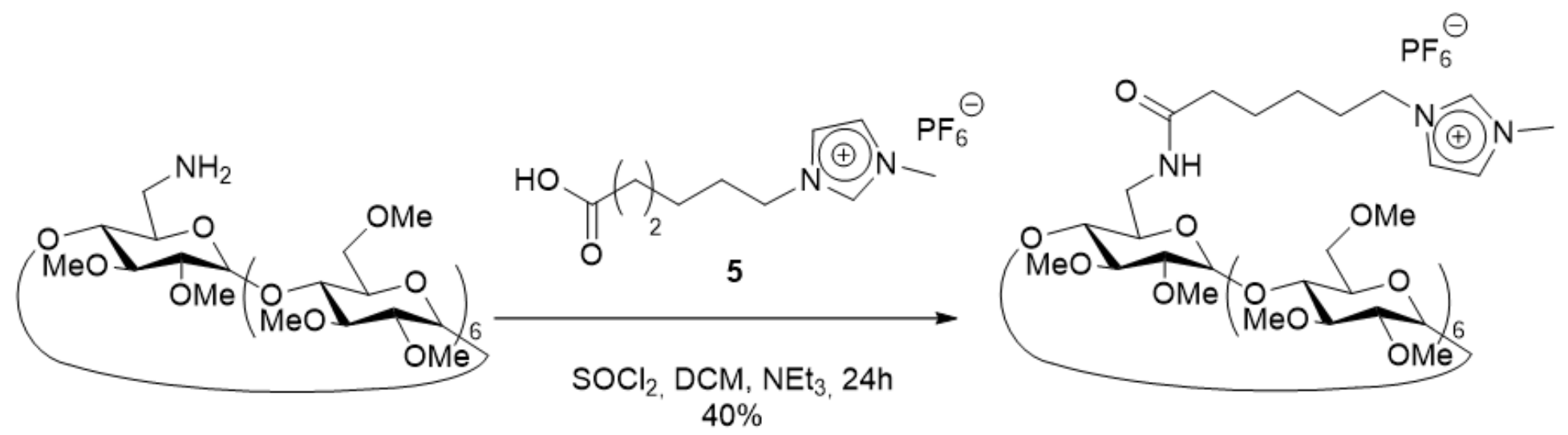

8

Figure 5

Synthesis of CD(OMe)-IL+PF6- 9 


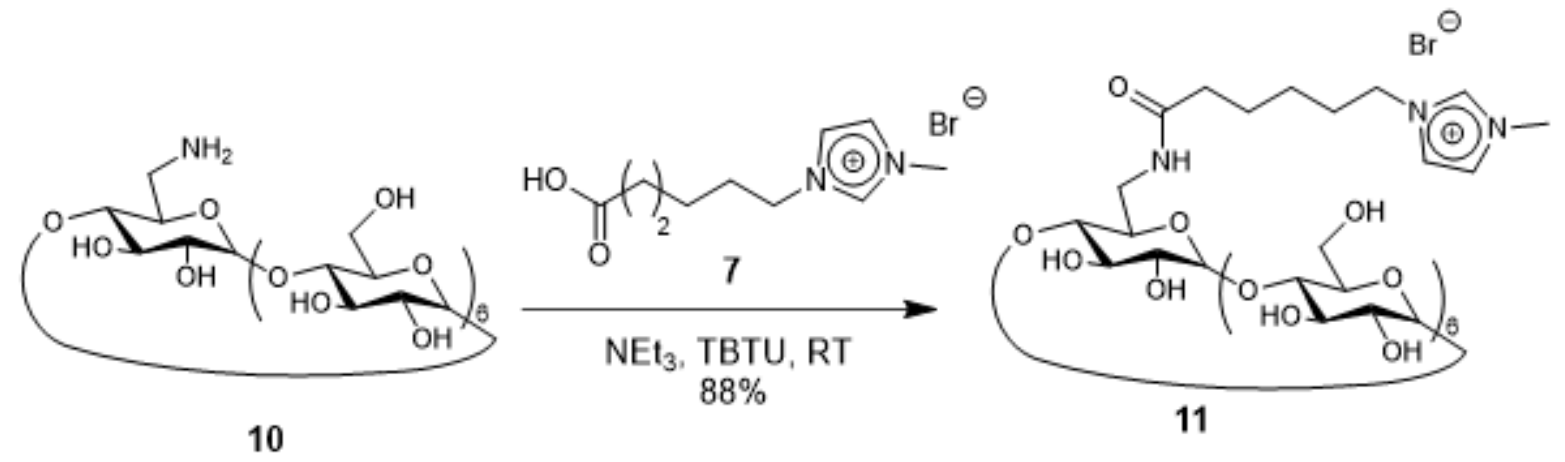

Figure 6

Synthesis of CD-IL+Br- 11

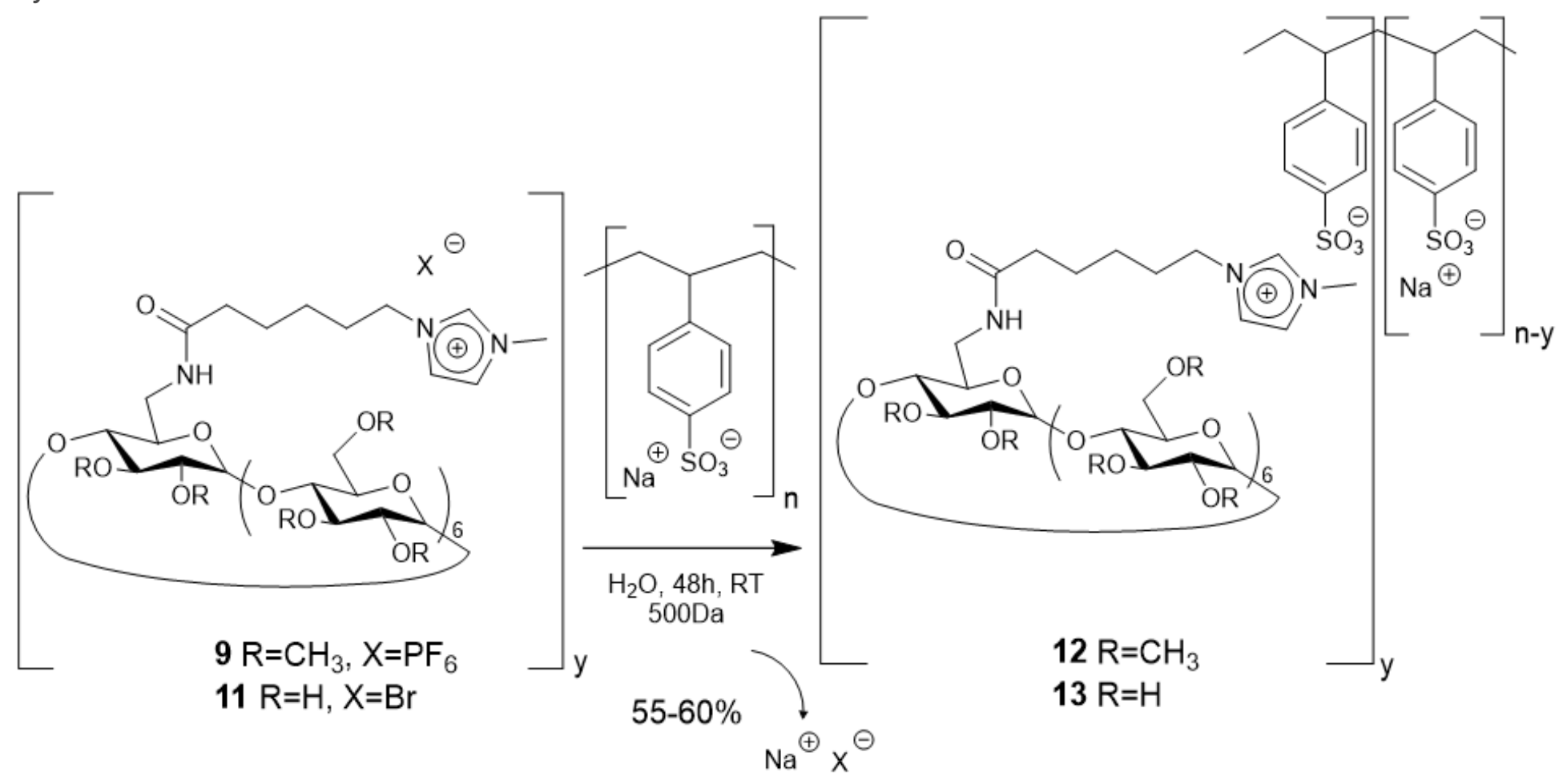

Figure 7

Synthesis of $C D(O M e)-I L+P S S-12$ and CD-IL+PSS- 13 by dialysis against deionized water 

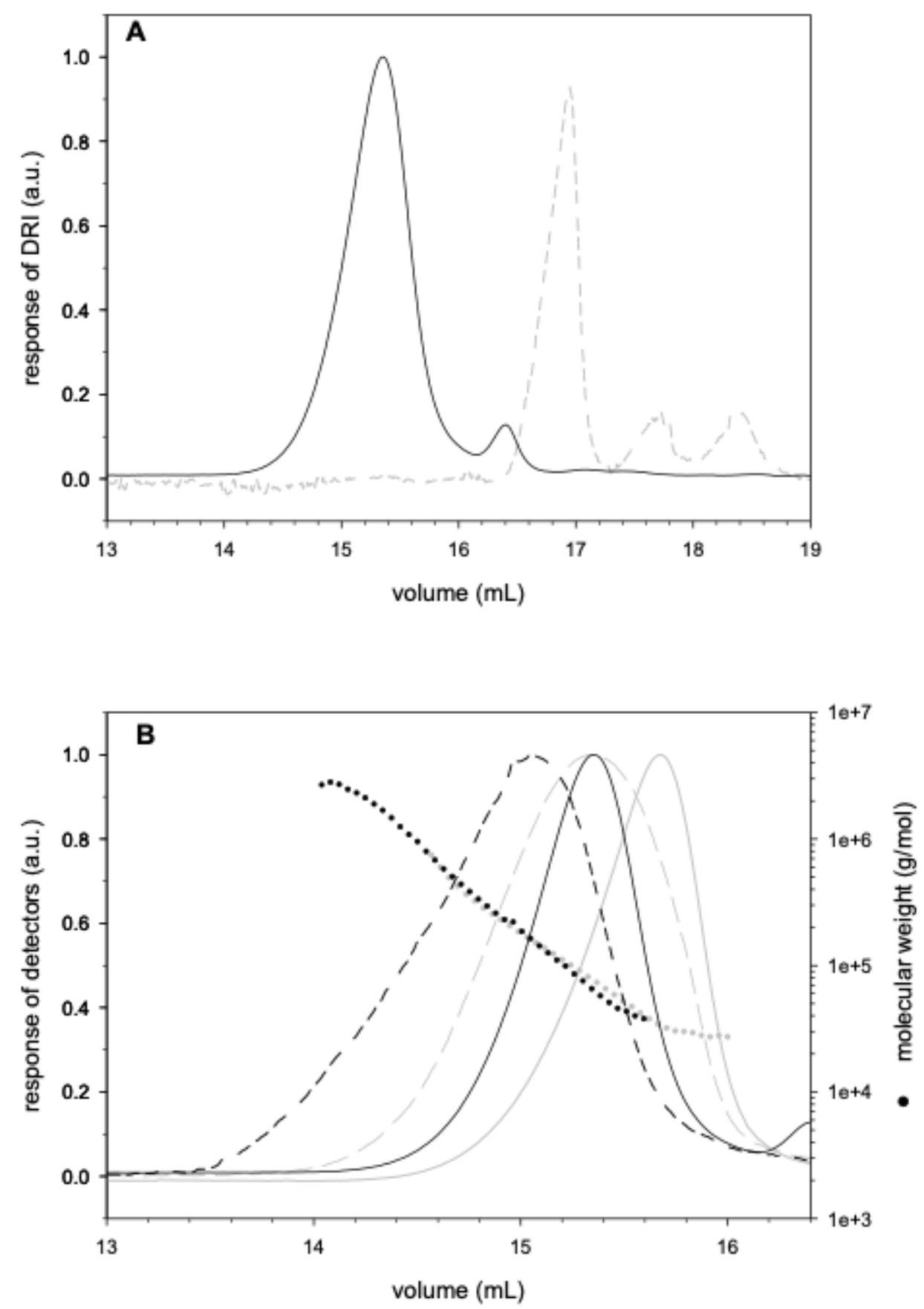

Figure 8

A) Elution profiles obtained by SEC from refractive index of $\mathrm{CD}(\mathrm{OMe})-\mathrm{IL}+\mathrm{Br}-11$ (gray dotted line) and $\mathrm{CD}\left(\mathrm{OMe}\right.$ )-LI+PSS- 12 with theoretical ratio 1/5 (black full line)) in LiNO3 $0.001 \mathrm{~mol} / \mathrm{L}$ at 25 $5^{\circ} \mathrm{C}$; B) Elution profiles obtained by SEC from refractive index (full lines) and Light scattering at $90^{\circ}$ (dotted lines) of PSS$\mathrm{Na}+$ (gray) and $\mathrm{CD}(\mathrm{OMe})-\mathrm{IL}+\mathrm{PSS}-12$ with theoretical ratio 1/5 (black) together with molecular weights distribution in LiNO3 $0.001 \mathrm{~mol} / \mathrm{L}$ at $25^{\circ} \mathrm{C}$ 


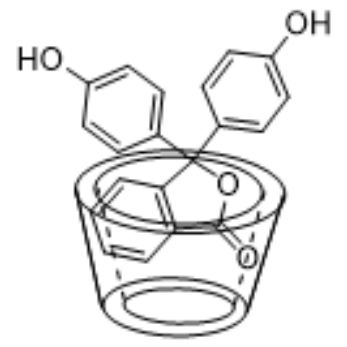

a)

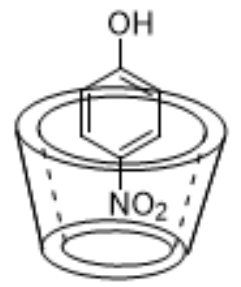

b)

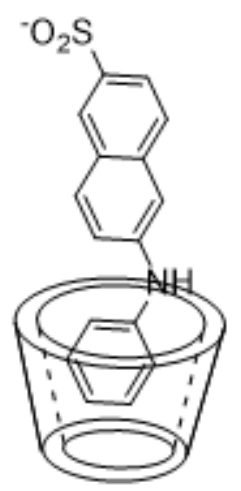

c)

Figure 9

Inclusion complexes studied: a) with phenolphtalein (PP), b) with p-nitrophenol (PNP), c) with anilinonaphthalene-6-sulfonic acid (2,6-ANS)

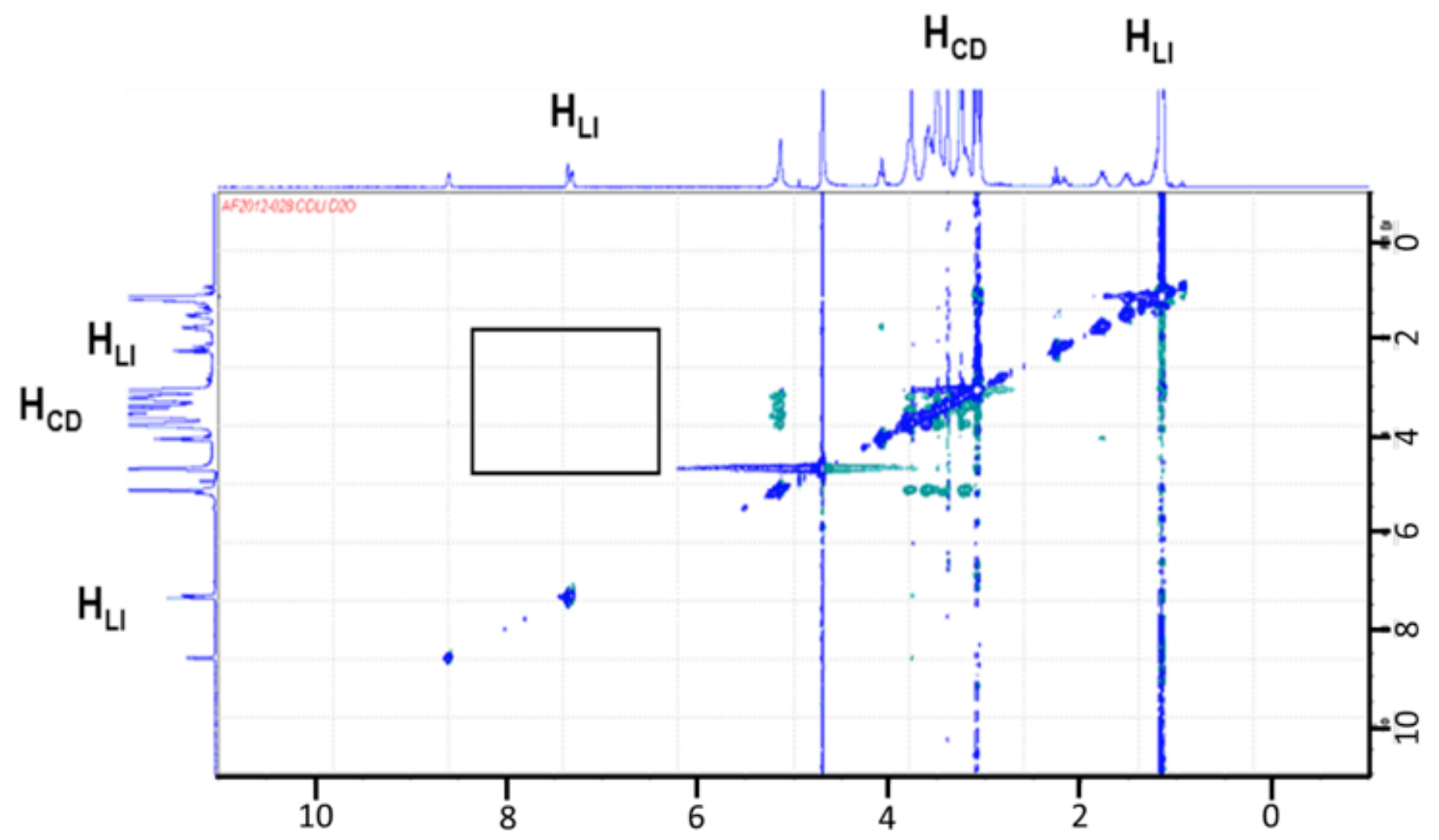

Figure 10

2D ROESY NMR spectrum (D2O, $300 \mathrm{MHz}, 400 \mathrm{~ms}, 16 \mathrm{mM}$ ) of CD(OMe)-IL+PF6- 9 

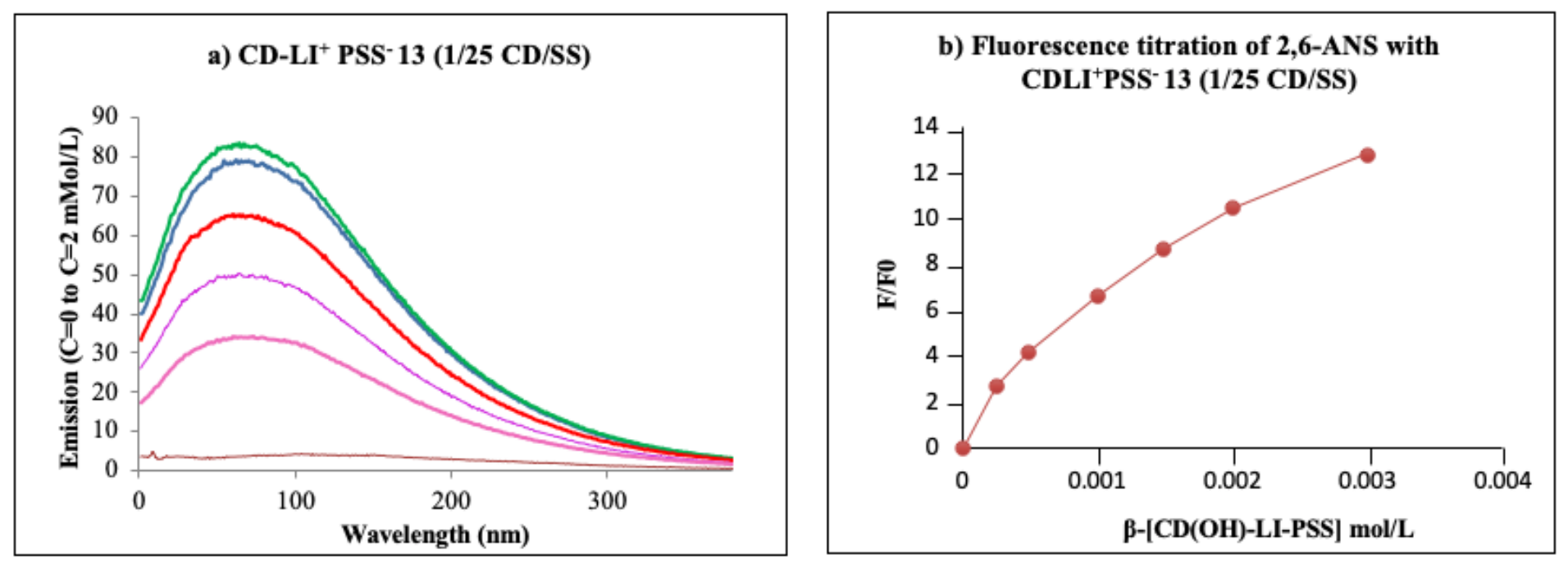

\section{Figure 11}

a) Fluorescent spectrum of 2,6-ANS in presence of various concentrations of CD-IL+PSS- 13 in aqueous buffer (concentration varying between 0 to $2 \mathrm{mM}$ ); b) Fluorescent titration of 2,6-ANS with CD-IL+PSS- 13 in aqueous buffer (concentration varying between 0 to $0.004 \mathrm{M}$ )

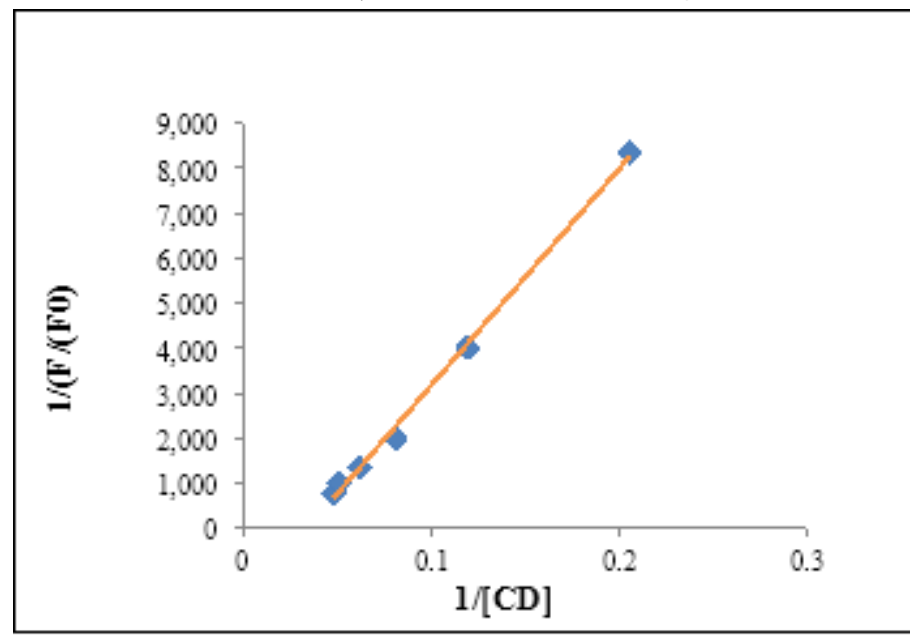

\section{Figure 12}

Plot of $1 /(F / F 0-1)=f(1 /[C D-L I+P S S-])$; the solid line is the linear adjustment. 


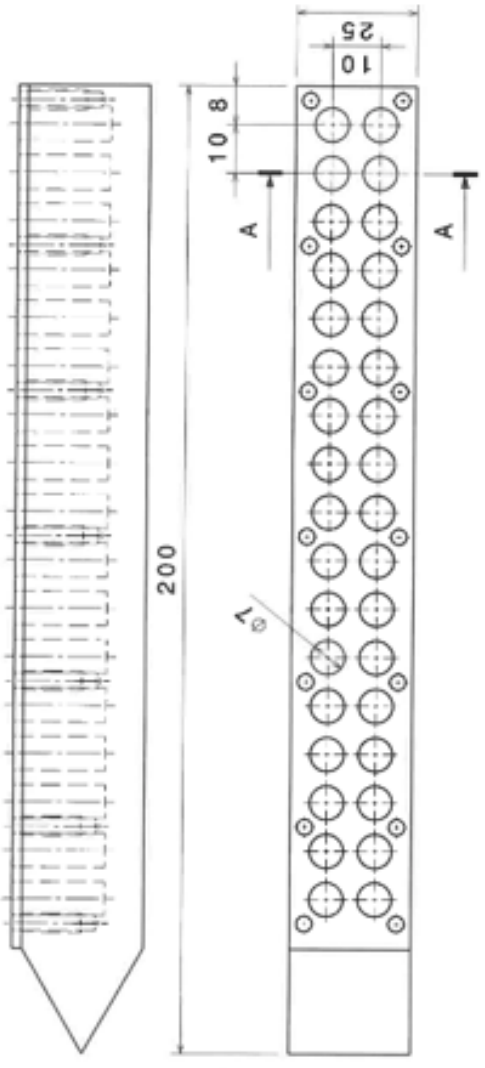

$\mathbf{A}$

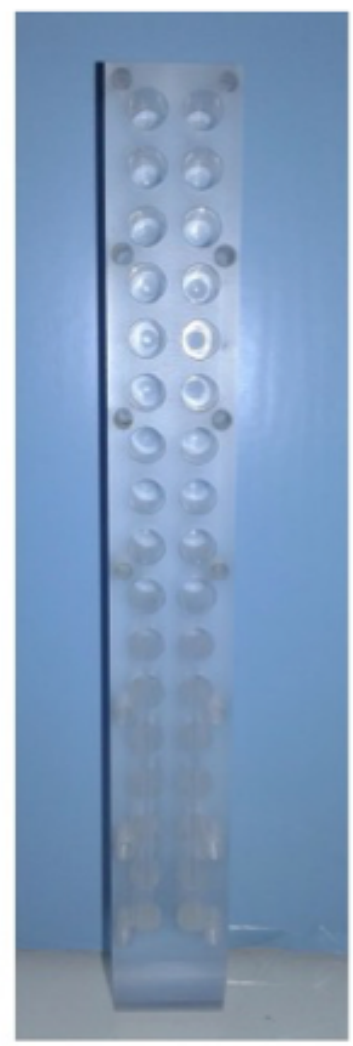

B

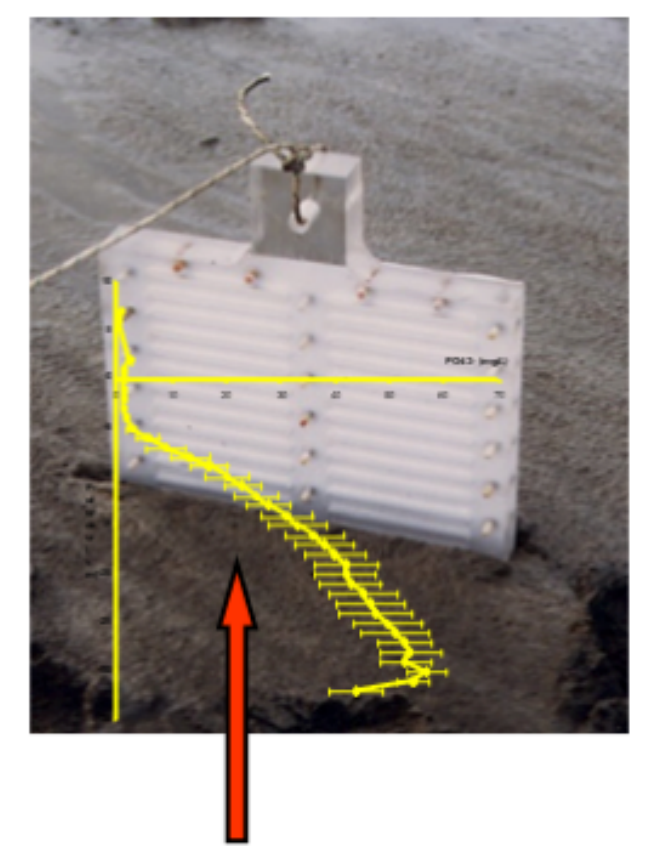

Concentration Gradient $d \mathrm{C} / d \mathbf{x}$

C

Figure 13

A. Dialyser Design; B. Dialyser used in this study; C. Dialyzer in sediment

\section{Supplementary Files}

This is a list of supplementary files associated with this preprint. Click to download.

- GraphicalAbstract.png

- exppart7aprilgouhier.docx 